\title{
Spinneret geometry modulates the mechanical properties of man-made cellulose fibers
}

\author{
Kaniz Moriam • Daisuke Sawada $\cdot$ Kaarlo Nieminen $\cdot$ Yibo Ma $\cdot$ \\ Marja Rissanen • Nicole Nygren • Chamseddine Guizani • Michael Hummel • \\ Herbert Sixta 10
}

Received: 4 August 2021 / Accepted: 17 September 2021 / Published online: 7 October 2021

(C) The Author(s) 2021

\begin{abstract}
The production of cellulose-based textile fibers with high toughness is vital for extending the longevity and thus developing a sustainable textile industry by reducing the global burden of microplastics. This study presented strategies to improve fiber toughness by tuning spinneret geometries. Experimental studies were conducted by spinning with different spinneret geometries and measuring the mechanical and structural properties of the spun fibers. In addition, numerical simulation tools were used to
\end{abstract}

Supplementary Information The online version contains supplementary material available at https://doi.org/10.1007/ s10570-021-04220-y.

K. Moriam · D. Sawada $\cdot$ K. Nieminen .

Y. Ma · M. Rissanen · N. Nygren .

C. Guizani · M. Hummel $\cdot$ H. Sixta $(\bowtie)$

Department of Bioproducts and Biosystems, School of Chemical Engineering, Aalto University, P.O Box 16300, 00076 Espoo, Aalto, Finland

e-mail: herbert.sixta@aalto.fi

K. Moriam

e-mail: most.moriam@aalto.fi

D. Sawada

e-mail: daisuke.sawada@aalto.fi

K. Nieminen

e-mail: kaarlo.nieminen@aalto.fi

Y. Ma

e-mail: yibo.ma@aalto.fi

M. Rissanen

e-mail: marja.rissanen@aalto.fi better understand the effects of spinneret geometry. The altering parameters of the spinneret geometries were the capillary diameters $\mathrm{D}$, the angle of the entry cone into the spinning capillary, and the ratio of capillary length to diameter L/D. The highest fiber toughness could be achieved at a capillary aspect ratio of 1 to 2 . The obtained maximum fiber toughness was $93 \mathrm{MPa}$ with a tensile strength of $60 \mathrm{cN} / \mathrm{tex}$ and a concomitant elongation of $16.5 \%$. For these fiber properties, a $13 \mathrm{wt} \%$ solution of a high-purity pulp with higher viscosity in [DBNH][OAc] was spun into a 1.3 dtex fiber using a D100 spinneret with a capillary of 1:1 length/diameter and an entrance angle of $8^{\circ}$. It

\author{
N. Nygren \\ e-mail: nicole.nygren@aalto.fi \\ C. Guizani \\ e-mail: chamseddine.guizani@aalto.fi \\ M. Hummel \\ e-mail: michael.hummel@aalto.fi
}


was noticeable that the microvoid orientations decreased almost linearly with increasing toughness of the fibers. The morphologies of the fibers were similar regardless of the spinneret geometries and the raw materials used in the spinning process. In summary, by modulating the spinneret geometries, Ioncell fibers obtained high toughness that have the potential to replace synthetic fibers.

Keywords Man-made cellulose fibers - Toughness of cellulose fiber · Spinneret geometry · Capillary aspect ratio of spinneret $\cdot$ Ionic liquid $\cdot$ Ioncell Technology $\cdot$ Dry-jet wet spinning

\section{Introduction}

Synthetic textiles dominate global textile production due to their low production cost. However, the unsustainable production processes for synthetic textiles, their lack of biodegradability and the resulting pollution by microplastic fibers are of global concern (Stone et al. 2020; Salvador et al. 2017; Royer et al. 2021). To promote the circular economy and sustainable textile production, synthetic textile should be gradually replaced by eco-friendly textiles. However, this implies that biodegradable textile fibers should have some properties that can currently only be achieved using synthetic fibers.

Man-made cellulose fibers produced from wood pulp derived from sustainable forestry or other lignocellulosic raw materials are more sustainable than synthetic fibers and cotton (Shen et al. 2010; Moriam et al. 2021a). With the development of lyocell fiber technology, a much more sustainable technology is now available to produce high-quality textiles compared to the viscose process (Sayyed et al. 2019b, 2019a; Jiang et al. 2020). Additionally, lyocell fiber technology also has the potential to upcycle cellulose-based waste textiles (Haslinger et al. 2019a, b; Wedin et al. 2019; Ma et al. 2018a, b), especially those made of natural cellulose fibers or viscose, into higher added value textile fibers.

The high toughness of cellulose-based textile fibers enables the development of sustainable textiles and upcycling of cellulosic waste textiles into durable textile fibers. However, commercially available high tenacity cellulose fibers compromise the good elongation property and vice versa (Sixta et al. 2015). Hence, a simultaneous increase of elongation and tenacity properties is required to enhance the toughness (the integral over the tenacity-elongation curve).

Ioncell ${ }^{\circledR}$ technology is a recently developed lyocell process to produce man-made cellulosic fibers from ionic liquid solutions by dry-jet wet spinning (Sixta et al. 2015; Asaadi et al. 2016; Michud et al. 2015). Ioncell is an environmentally friendly process and considered as an alternative to the viscose and $\mathrm{N}$ methylmorpholine $N$-oxide (NMMO)-based Lyocell processes (Michud et al. 2015; Elsayed et al. 2020). The ionic liquid '1,5-diazabicyclo [4.3.0] non-5-ene acetate [DBNH][OAc]' is used as an excellent cellulose solvent allowing for a rapid dissolution at moderate temperatures and subsequent shaping into continuous filaments (Hummel et al. 2016). Highly orientated cellulose fibers with high tenacity are obtained by coagulation in a cold-water bath (Hauru et al. 2014).

The process parameters, including extrusion velocity, draw ratio, airgap, spinneret geometry, and coagulation bath temperature, considerably influence the mechanical properties of man-made cellulose fiber produced via lyocell process (Hauru et al. 2014; Michud et al. 2016). Michud et al. previously reported the effect of spinneret diameter $(150$ vs. $100 \mu \mathrm{m})$, draw ratio, and coagulation bath temperature on the structural and mechanical properties of the cellulose fiber (Michud et al. 2016). Guizani et al. presented the effect of air gap conditioning on the mechanical properties of the fibers using a monofilament spinning plant (Guizani et al. 2020b). Previously, two studies were performed to observe the effect of spinneret aspect ratio (L/D) on the Ioncell fiber properties. Hauru et al. reported that a L/D of 2 improved the Ioncell fiber orientation compared to a shorter L/D of 0.2 (Hauru et al. 2014). Later, Guizani et al. further justified that the increase in L/D leads to better mechanical properties of the spun fibers (Guizani et al. 2020a). However, both studies were done with a monofilament spinning system, which was only conditionally representative of real spinning conditions. Moreover, there is a lack of systematic knowledge about the geometry of the spinneret capillaries, such as the length-to-diameter ratio of the capillary, the entrance cone geometry, and the use of multi-hole spinnerets. 
Spinneret geometry is one of the important spinning parameters that affects the spinnability, the structural properties, and the fiber mechanical properties (Michud et al. 2016; Wang et al. 2018). The influence of the spinneret diameter on the mechanical properties of the NMMO- Lyocell fibers was investigated. Mortimer et al. reported that the narrower the spinneret, the shorter the draw length. In addition, the die swell effect is smaller for the spinneret with holes of a lower diameter due to the efficient cooling (Mortimer and Péguy 1995).

The effect of the spinneret geometry in the solution flow during spinning was investigated rigorously in a series of publications by Xia et al. for the dry-jet wet spinning of the cellulose/1-butyl-3-methylimidazolium [BMIM]CL solution (Xia et al. 2014, 2015, 2016). Xia et al. studied the effect of the entrance angle and the influence of the capillary length in the flow behavior of the spinning solution using numerical simulation (Xia et al. 2014). According to their study, longer spinneret aspect ratio helped to stabilize the viscosity of the cellulose/IL solution promoting the smooth solution flow. Furthermore, the study reported that the die swell effect was reduced by a shorter spinneret entrance angle and an increased length of the exit channel. A shorter entrance angle reduced the velocity gradient along the flow direction and a longer capillary length promoted the relaxation of the polymer chain. In addition, the longer capillary promoted a stable viscosity of the cellulose solution compared to the shorter capillary. The apparent viscosity remained stable due to the molecular orientation in the outlet channel.

Kirichenko et al. suggested the use of rectangular spinnerets instead of the circular spinnerets to reduce the irregularities of the diameter of the spun Capron yarn (Kirichenko et al. 1977). According to their study, the fluctuation of the airflow and the difference in heat transfer from the filaments to the air depend on the arrangement of the spinneret hole. The cooling conditions of the filaments were more uniform when the spinneret holes were arranged in straight lines compared to the concentric circles due to the transverse unilateral air flow. Due to the uniform cooling in the airgap, the rectangular arrangement of spinneret hole produced yarn that had more regularity in the yarn diameter.

We have previously shown that a longer capillary length of the spinneret for a given diameter significantly increased the fiber toughness under otherwise identical spinning conditions (Moriam et al. 2021b).According to that study, Ioncell fiber achieved a modulus of toughness of 83.3 MPa, which presented the potential of Ioncell fibers to have higher strength and toughness than any other existing cellulose fibers. The long-term goal of the study was to reach the toughness of polyester fibers (128 MPa), a common synthetic textile fiber (Moriam et al. 2021b). As a continuation of the previous study, we have used different spinneret geometries with varying spinneret shape (circular to rectangular hole arrangement), entrance angle, spinneret diameter, hole number, and capillary length to observe their effects in mechanical properties in the final fiber. In addition, the influence of spinneret geometries on the solution flow was investigated using numerical simulation. Furthermore, we investigated the combined effect of the optimized spinneret geometry and different pulps (standard grade and high purity pulp) on the mechanical properties of the spun fibers. Finally, the structural properties of the high toughness fibers and their morphological properties were reported.

The effect of spinneret geometry in the spun fibers' mechanical properties has not been published before systematically for dry-jet wet spinning. This work will present new insight of improving toughness of manmade cellulose fibers toughness by tuning the spinneret geometries.

\section{Experimental part}

Raw materials

This study used high-purity pine pre-hydrolysis Kraft pulp additionally purified with cold caustic extraction produced by Georgia Pacific denoted as high purity grade pulp or HPG-pulp (intrinsic viscosity, CUEN, ISO $5351 / 1$, of $594 \mathrm{ml} / \mathrm{g} ; \mathrm{M}_{\mathrm{n}}=96.5 \mathrm{~kg} / \mathrm{mol}$ and $\mathrm{M}_{\mathrm{w}}=$ $209 \mathrm{~kg} / \mathrm{mol}$, calculated by GPC-MALLS, hemicellulose $0.7 \%$ ) and birch pre-hydrolysis Kraft pulp denoted as STG-pulp (Standard grade Pulp) (intrinsic viscosity $482 \mathrm{ml} / \mathrm{g} ; M_{\mathrm{n}}=49.3 \mathrm{~kg} / \mathrm{mol}$ and $M_{\mathrm{w}}=$ $161.7 \mathrm{~kg} / \mathrm{mol}$; hemicellulose $6.8 \%$ ) (Moriam et al. 2021b). Equimolar amount of 1,5-diazabicyclo [4.3.0] non-5-ene (99\% Fluorochem, UK) and acetic acid (100\% Merck, Germany) were used to synthesize the Ionic liquid 1,5-diazabicyclo [4.3.0] non-5-ene acetate 
[DBNH][OAc] for the dissolution of cellulose. Elmer $\mathrm{GmbH}$, Austria provided 10 different spinneret geometries having rectangular hole distributions (Fig. S1) and, as a reference, the spinneret with circular hole distribution (Fig. S1) obtained from Enka Tecnica, Germany (Table 1).

Dope preparation and rheology

The grinded pulps were dissolved in melted [DBNH] [OAc] for $90 \mathrm{~min}$ at $80^{\circ} \mathrm{C}$ using a vertical kneader system. The cellulose concentration of the dope was 13-15 wt \%. After dissolution, the dopes were filtered using a press filtration unit (metal filter fleece, absolute fineness of 5-6 $\mu \mathrm{m}$ ). The rheological properties of the dopes were measured using the Anton Paar Physica MCR 302 rheometer containing parallel plate geometry (plate diameter $25 \mathrm{~mm}$ and gap size $1 \mathrm{~mm})$. A dynamic sweep test $\left(100-0.1 \mathrm{~s}^{-1}\right)$ was performed to record the complex viscosity and the dynamic moduli (G' and G'). Zero shear viscosity was calculated using a cross viscosity model (Michud et al. 2016) assuming the validity of the Cox-Merz rule.

Dry-jet wet spinning

Dry-jet wet spinning of the cellulose solutions (dopes) were performed using a customized laboratory piston spinning unit (Fourné Polymertechnik, Germany). The molten dope was extruded through spinnerets. The filaments were coagulated in a water bath $\left(8-10{ }^{\circ} \mathrm{C}\right)$ keeping an airgap of $1 \mathrm{~cm}$ and further guided by Teflon rollers to the godet (velocity varied from 5 to $95 \mathrm{~m} \mathrm{~min}^{-1}$ depending on the obtained draw ratios). The fibers were washed with hot water $\left(80^{\circ} \mathrm{C}\right)$ for $2 \mathrm{~h}$ under continuous magnetic stirring (the water was changed every $30 \mathrm{~min}$ ). Fibers were air-dried after washing.

\section{Numerical simulation}

The velocity and shear rate distributions affecting the molecular alignment of the cellulose strands in the cellulose solutions were evaluated by simulating the flow of the cellulose solution using the COMSOL Multiphysics software using the Computational Fluid Dynamics module. Prior to this, the viscosity crossmodel parameters were estimated from shear rate viscosity data of the dope by fitting the model to the experimental data using Wolfram Mathematica (Moriam et al. 2021b). Accordingly, the simulation of velocity and shear rate distributions in a spinneret channel was done in the Computational Fluid Dynamics module of COMSOL, assuming laminar flow and employing the fitted cross-model to describe the shear rate dependence of the viscosity. By virtue of the axisymmetric spinneret channels, it suffices to create a corresponding $2 \mathrm{D}$ geometry in which to carry out the simulation.

Table 1 The list of spinnerets

\begin{tabular}{|c|c|c|c|c|c|c|}
\hline $\begin{array}{l}\text { Name }(\text { Number of } \\
\text { holes } \times \text { diameter } \times \text { aspect ratio) }\end{array}$ & $\begin{array}{l}\mathrm{L} / \\
\mathrm{D}\end{array}$ & $\begin{array}{l}\text { Diameter } \\
(\mu \mathrm{m})\end{array}$ & $\begin{array}{l}\text { Hole } \\
\text { number }\end{array}$ & $\begin{array}{l}\text { Hole density (holes/ } \\
\mathrm{cm}^{2} \text { ) }\end{array}$ & $\begin{array}{l}\text { Entrance } \\
\text { angle }\end{array}$ & Hole distribution \\
\hline $504 \times 100 \times 0.2$ & 0.2 & 100 & 504 & \multirow[t]{2}{*}{221} & \multirow[t]{10}{*}{$8^{\circ}$} & \multirow{10}{*}{$\begin{array}{l}\text { Rectangular } \\
\quad \text { (Fig. S1) }\end{array}$} \\
\hline $504 \times 100 \times 1.0$ & 1.0 & 100 & 504 & & & \\
\hline $216 \times 100 \times 1.5$ & 1.5 & 100 & 216 & 95 & & \\
\hline $216 \times 100 \times 2.0$ & 2.0 & 100 & & & & \\
\hline $216 \times 100 \times 4.0$ & 4.0 & 100 & & & & \\
\hline $216 \times 100 \times 5.0$ & 5.0 & 100 & & & & \\
\hline $216 \times 80 \times 0.2$ & 0.2 & 80 & & & & \\
\hline $216 \times 80 \times 1.0$ & 1.0 & 80 & & & & \\
\hline $216 \times 50 \times 0.2$ & 0.2 & 50 & & & & \\
\hline $216 \times 50 \times 1.0$ & 1.0 & 50 & & & & \\
\hline $400 \times 100 \times 0.2$ & 0.2 & 100 & 400 & 58 & $60^{\circ}$ & $\begin{array}{l}\text { Circular } \\
\text { (Fig. S1) }\end{array}$ \\
\hline
\end{tabular}


In the simulation, the integration of the scalar product of the shear stress and shear rate over the channel geometry gives a quantity that summarizes the work per unit time accomplished by the shear forces on the viscous fluid in the channel- the shear power.

Considering an infinitesimal portion of the flow, we can conclude the shear power absorbed to be

$d P=\sigma \cdot \dot{\gamma} d V$.

Here $d P$ is the (infinitesimal) power absorbed by the volume element $d V$ whereas $\sigma$ and $\dot{\gamma}$ are the shear stress and shear rate, respectively. Expressing the shear stress as the viscosity $\mu(\dot{\gamma})$ times the shear rate and integrating over the volume of the channel renders

$P=\int \mu(\dot{\gamma}) \dot{\gamma}^{2} d V$

Equipped with the previous equation, we can obtain estimates for the power absorbed in the channels of the different spinneret types by COMSOL simulation.

Tensile properties and birefringence

The tensile properties (tenacity $(\mathrm{cN} /$ tex); elongation at break (\%) and linear density (dtex)) of the spun fiber samples were measured both in conditioned and wet state using a Favigraph device (Textechno, Germany). Prior to measurement, the fibers were conditioned in $20 \pm 2{ }^{\circ} \mathrm{C}$ and relative humidity of $65 \pm 2 \%$. For each measurement, a total of 20 individual fibers were measured using $20 \mathrm{cN}$ load cell and $20 \mathrm{~mm}$ gauge length. The modulus of toughness was calculated using the initial slope of the individual stress strain curves.

The total orientation of the fibers was measured using a polarized light microscope (Zeiss Axio Scope) connected with a $5 \lambda$. Berek compensator. The birefringence $\Delta \mathrm{n}$ was calculated from the retardation of the polarized light divided by the thickness of the fiber assuming cellulose density of $1.5 \mathrm{~g} / \mathrm{cm} 3$ (Männer et al. 2009). The total orientation was calculated from birefringence $\Delta \mathrm{n}$ divided by the maximum value (0.062) of the cellulose's birefringence (Adusumalli et al. 2009; Lenz et al. 1994).

Wide angle X-ray Scattering (WAXS)

$\mathrm{X}$-ray diffraction data of the precursor fibers were collected in the transmission setting of a SmartLab instrument (RIGAKU) operated at $45 \mathrm{kV}$ and $200 \mathrm{~mA}$. Cellulose fibers were grinded using a Wiley mill with $60 \mu \mathrm{m}$ mesh size. The samples were then pressed into disks using a pellet press instrument with constant force for $30 \mathrm{~s}$. Powder diffraction data were collected from $5^{\circ}$ to $60^{\circ} 2 \theta$ by $\theta / 2 \theta$ setting. Scattering profile were corrected for smoothing, subtracting air scattering, and subtracting inelastic contribution. Guizani et al. presented the detailed smoothing procedure which was used to subtract the amorphous cellulose contribution from remained elastic scattering profile (Guizani et al. 2020a). Thus, estimated amorphous contribution $\left(I_{b k g}(2 \theta)\right)$ is used to estimate the crystallinity index $(\mathrm{CI})$ using a range from $9^{\circ}$ to $50^{\circ}$ 2ө:

$C I=100 * \frac{\int I(2 \theta) d 2 \theta-\int I_{b k g}(2 \theta) d 2 \theta}{\int I(2 \theta) d 2 \theta}$

The background corrected profiles were fitted with four pseudo-Voigt functions for (1̄̄0), (110), (020), and (002) peaks for cellulose II (Langan et al. 2001) using a LMFIT software (Newville et al. 2016). The (002) peak was added because there was a visible shoulder for the peak in this $\theta / 2 \theta$ and transmission geometry. The Scherrer equation was used to estimate the crystal widths $\left(\mathrm{CW}_{\mathrm{hkl}}\right)$ as follows:

$C W_{h k l}=\frac{K \lambda}{\beta_{h k l} \cos \theta}$

where $K=0.90$ is the shape factor, $\lambda$ is the $X$-ray wavelength, $\beta_{\mathrm{hk} 1}$ is the full width at half maximum (FWHM) of the diffraction peak in radians, and $\theta$ is the diffraction angle of the peak. Due to the significant overlap of (110) and (020) peaks, the crystal widths were reported as average values.

The orientation distribution between fiber axis and the crystallographic (020) lattice plane $\left(\cos ^{2} \varphi_{020}\right)$ was estimated using azimuthal scans obtained from the (020) lattice plane of cellulose II allomorph at $21.9^{\circ}$ $2 \theta$.

$\cos ^{2} \varphi_{020}=\frac{\int_{0}^{\pi / 2} I\left(\varphi_{020}\right) \sin \varphi_{020} \cos ^{2} \varphi_{020} d \varphi}{\int_{0}^{\pi / 2} I\left(\varphi_{020}\right) \sin \varphi_{020} d \varphi}$

The orientation distribution from equatorial diffraction further converted to the orientation distribution between fiber and crystallographic c-axis $\cos ^{2} \varphi_{c}$ assuming cylindrical symmetry: 
$\cos ^{2} \varphi_{c}=1-2 \cos ^{2} \varphi_{020}$

Hermans orientation parameter $\left(f_{W A X D}\right)$ was estimated by:

$f_{W A X D}=\frac{3 \cos ^{2} \varphi_{c}-1}{2}$.

\section{Small angle X-ray Scattering (SAXS)}

SAXS experiment was performed in a transmission mode of Xeuss 3.0 (Xenocs) $\mathrm{CuK} \alpha \mathrm{X}$-ray instrument operated at $50 \mathrm{kV}$ and $0.6 \mathrm{~mA}$. Fiber samples were placed vertically on the sample holder and X-ray was radiated on the longitudinal side of the fiber. The sample chamber was kept under vacuum condition (= $0.16 \mathrm{mbar})$ during the measurement. The scattering intensity was recorded on a 2D detector Eiger2 R 1 M (Detris) and later corrected for the cosmic background.

The azimuthal profile was obtained in a scattering vector Q-range of $0.016-0.002 \AA^{-1}$ with intensity corrected for the detector orientation, acquisition time, and transmitted flux. The data were not corrected for the sample thickness. The obtained azimuthal profiles were fitted with a pseudo-Voigt function with a constant background. The fitted azimuthal profile was used to estimate the orientation distribution of the equatorial streak $\cos ^{2} \varphi_{\text {streak }}$ :

$\cos ^{2} \varphi_{\text {streak }}=\frac{\int_{0}^{\pi / 2} I\left(\varphi_{\text {streak }}\right) \sin \varphi_{\text {streak }} \cos ^{2} \varphi_{\text {streak }} d \varphi}{\int_{0}^{\pi / 2} I\left(\varphi_{\text {streak }}\right) \sin \varphi_{\text {streak }} d \varphi}$

Then it was converted into the orientation parameter $\left(f_{S A X S}\right)$ in the same fashion as the Hermans orientation parameter is estimated from the equatorial diffraction assuming cylindrical symmetry:

$\cos ^{2} \varphi_{c}=1-2 \cos ^{2} \varphi_{\text {streak }}$

$f_{S A X S}=\frac{3 \cos ^{2} \varphi_{c}-1}{2}$

Scanning electron microscopy (SEM) imaging

SEM imaging was performed by using a Zeiss Sigma VP (manufactured country Germany). For crosssection imaging, the fiber was prepared by cryofracture in liquid nitrogen. A bundle of fiber was first dipped into liquid nitrogen and snapped. The fractured fiber bundle was then glued onto the conductive support. The samples were sputter-coated with gold to ensure electric conductivity (20 mA current with $90 \mathrm{~s}$ coating time). The secondary electron images were taken at a $3 \mathrm{kV}$ operating voltage at $\sim 5 \mathrm{k}$ to $10 \mathrm{k}$ magnification.

\section{Results and discussion}

Rheology of cellulose solutions

The spinning performance is predominantly modulated by the rheological properties of the dope (Asaadi et al. 2018). The rheology properties of a cellulose solution influence the spinnability of the spinning solution. According to previous studies, cellulose solution in [DBNH][OAc] followed the optimum characteristics of a spinnable solution having zero shear viscosity (20,000-30,000 Pa.s), crossover point around $4000 \mathrm{~Pa}$, and angular frequency around $1 \mathrm{~s}^{-1}$ (Sixta et al. 2015; Hummel et al. 2016; Michud et al. 2015). In this study, for STG cellulose solutions, the average spinning temperature was $72 \pm 6{ }^{\circ} \mathrm{C}$, in which the cellulose solutions had average zero shear viscosity $\sim 34,000 \mathrm{~Pa}$; complex viscosity at the crossover point, $\mathrm{G}^{\prime}=\mathrm{G}^{\prime \prime}, \sim 3900 \mathrm{~Pa}$ and the angular frequency, $\omega \sim 0.7 \mathrm{~s}^{-1}$ (Fig. 1). In addition, the denser hole containing spinneret (504 holes) reduced spinning temperature slightly compared to 216-hole spinneret (Table S2). With the increasing number of holes, the mass flow increases resulting in pressure reduction. To maintain the extrusion pressure, the temperature needs to be reduced slightly. Additionally, since the cooling in the air gap is lower with a high number of holes and hole density, the temperature of the supplied spinning solution can be reduced.

Due to having a higher degree of polymerization (DP) and higher molecular weight of HPG pulp, the rheological properties of HPG cellulose solution (13 $\mathrm{wt} \%$ ) are changed significantly compared to the STG cellulose solution (Fig. 1). Interestingly, on average, the spinning temperature for HPG solution was increased by only $\sim 6{ }^{\circ} \mathrm{C}$ (from 72 to $78^{\circ} \mathrm{C}$ ) although the HPG solution's zero shear viscosity was higher at the spinning temperature by a factor of 1.9 compared to the STG solution (Fig. 1). 
(a)

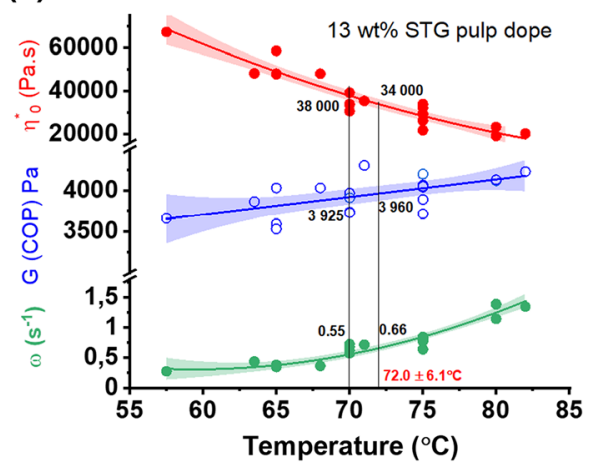

Fig. 1 The rheological parameters including zero shear viscosity $\eta_{0}{ }^{*}$, dynamic modulus at crossover point; G(COP) and angular frequency at crossover point; $\omega(\mathrm{COP})$; of a $13 \mathrm{wt} \%$

To observe the effect of the different spinneret geometries, initial spinning trials using different spinneret geometries were performed with STG cellulose solutions with $13 \mathrm{wt} \%$ concentration. Later, the HPG cellulose solution was used in combination with optimized spinneret geometry to observe the effect of pulp.

Numerical simulations using cellulose (STG pulp) solution in ionic liquid [DBNH][OAc]

Numerical simulations were performed initially for STG cellulose solution (based on the rheology) inside the spinneret to observe the effect of spinneret geometries in the flow behavior of the cellulose solution. The impact of the shear flow was estimated by integrating the product of the shear velocity and the shear rate over the different capillaries (Fig. 2a,b). According to Xia et al. spinneret aspect ratio and entrance angle determined the IL/cellulose solution flow (Xia et al. 2014, 2015). In this study, the entrance angle of the spinneret influenced the shear power of the STG cellulose dopes inside the spinneret (Fig. S2). The shear power increased significantly due to a lower entrance angle of $8^{\circ}$ (rectangular hole distribution) compared to an entrance angle of $60^{\circ}$ (circular hole distribution). Previous studies suggested that a shorter entrance angle can be useful to promote efficient solution flow inside the spinneret (Xia et al. 2014). In another study, it was explained that the lower entrance angle reduced the velocity gradient along the flow direction resulting in the extension of the flow length, (b)

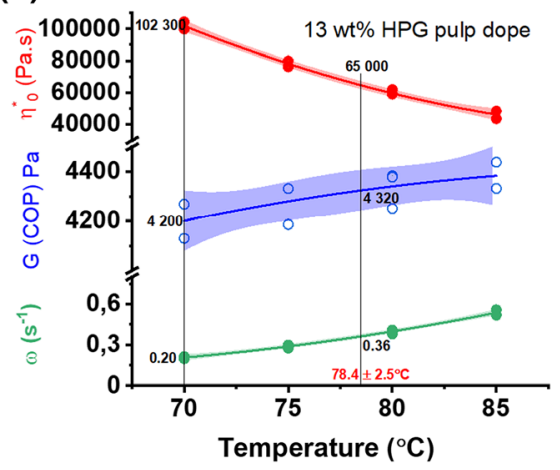

STG and $\mathbf{b} 13 \mathrm{wt} \%$ HPG cellulose solutions in [DBNH][OAc] as a function of temperature. Polynomial fit, $95 \%$ confidence band (Origin software)

which provides the polymer chains enough time to relax (Xia et al. 2016).

The variation of the diameter of the exit channel significantly influences the velocity, pressure, and the shear rate fields in the spinneret. At constant mass flow, variation of the diameter results in different extrusion velocities that affects the shear rate in the spinneret. The deformation energy might be more dissipated in the spinneret with a smaller diameter compared to the wider diameter (Xia et al. 2016). For the spinneret with entrance angle $8^{\circ}$, the diameters were varied from 100, 80, and $50 \mu \mathrm{m}$. Earlier studies explained that reduction of the spinneret's hole diameter promoted efficient cooling of the fluid filament in the airgap due to the increased surface area of the filament (Michud et al. 2016; Mortimer and Peguy 1996). Due to the smaller hole diameter, a shorter draw ratio was sufficient to achieve the desired titer. However, the use of $50 \mu \mathrm{m}$ diameter spinnerets was not successful. During the spinning the piston pressure inside the spinneret exceeded the optimum pressure at a higher draw ratio which causes fiber breakages. The use of this D50 spinneret may require a lower cellulose concentration in the dope for successful spinning (less than $13 \mathrm{wt} \%$ ). Hence, the numeric simulations of the cellulose solutions' flow behavior inside the D50 spinneret were not performed. The viscous power (shear power) of the STG cellulose solution into both D100 and D80 spinnerets varied with the change in capillary length. In case of D100 spinnerets, the spinneret capillary aspect ratio increased from L/D 0.2 to L/D 1.0, 1.5, 2, 4, and 5 . The shear power increased by a factor of 1.15 when the 

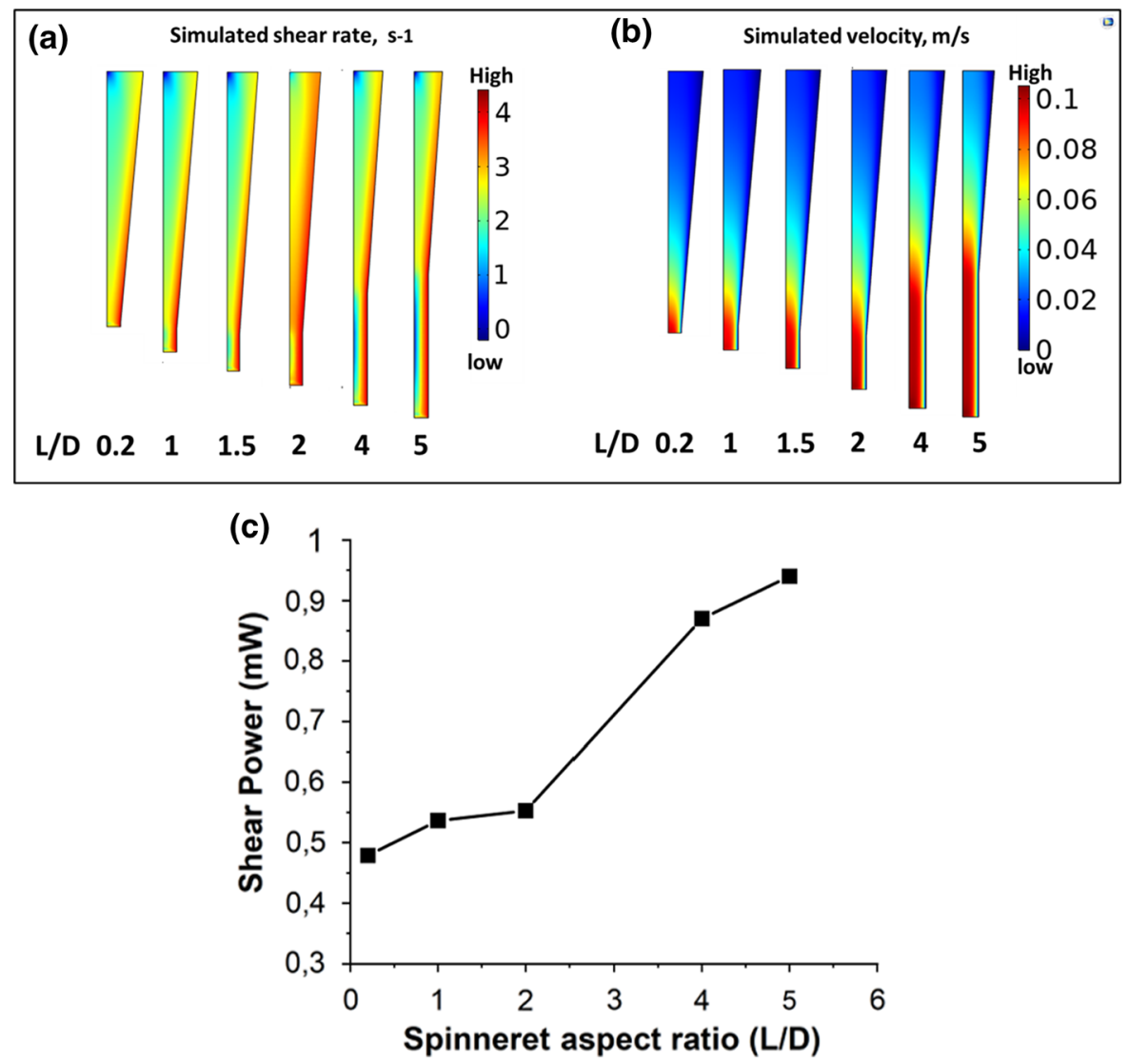

Fig. 2 a Logarithm of the simulated shear rate (left) and b simulated velocities for the D100 spinnerets (L/D 0.2, 1,1.5, 2, 4,5 ); c Simulated shear power with increasing capillary lengths

capillary aspect ratio was increased from L/D 0.2 to 1.0-2.0, while when increased to L/D 4 and 5, the shear powers increased by a factor of 1.8 to 1.9 , respectively (Fig. 2c). On the other hand, for D80 spinnerets, the shear power increased slightly for the enhanced capillary length (L/D 0.2 to 1.0 ) (Fig. S3).

Investigation of the effect of spinneret geometries on the mechanical properties of fibers

\section{Spinneret geometries: titer (linear densities) and spinnabilities}

The spinnability of a cellulose solution is defined by the stretchability of a fluid filament in the airgap for a defined time without breakage. This filament stretchability is characterized by the ratio of take-up velocity to extrusion velocity named as draw ratio (DR). The linear density (titer) of the spun fibers are adjusted by of the spinnerets with $100 \mu \mathrm{m}$ diameter for the $13 \mathrm{wt} \%$ STG cellulose solutions in [DBNH][OAc]

the DR (Hauru et al. 2014). In several previous research studies, the spinnability of a cellulose solution spun with $100 \mu \mathrm{m}$ hole diameter spinnerets was defined as follows: DR $<2$ (titer $>6$ dtex); nonspinnable, DR 2-8 (titer 6- 2 dtex) -poor, DR 8-14 (titer 2- 1 dtex) -good and DR $>14$ (titer $<1$ dtex) excellent (Asaadi et al. 2016, 2018; Haslinger et al. 2019a).

Compared to D100 spinnerets, the fibers with target titer were produced at a lower DR using D80 spinnerets (Fig. 3a,b). The decrease in spinneret diameter reduces the draw length (Mortimer and Péguy 1995). Based on the titer measurement, the spinnability can be defined as follows using a spinneret with a hole diameter of $80 \mu \mathrm{m}$ : DR $<5$ (titer $>2)$-poor, DR 5-9 (2-1 dtex) -good and $\mathrm{DR}>9$ (titer $<1$ dtex) -excellent. In addition, the spinnability was determined in terms of the minimum titer achieved and considering the spinning time of 

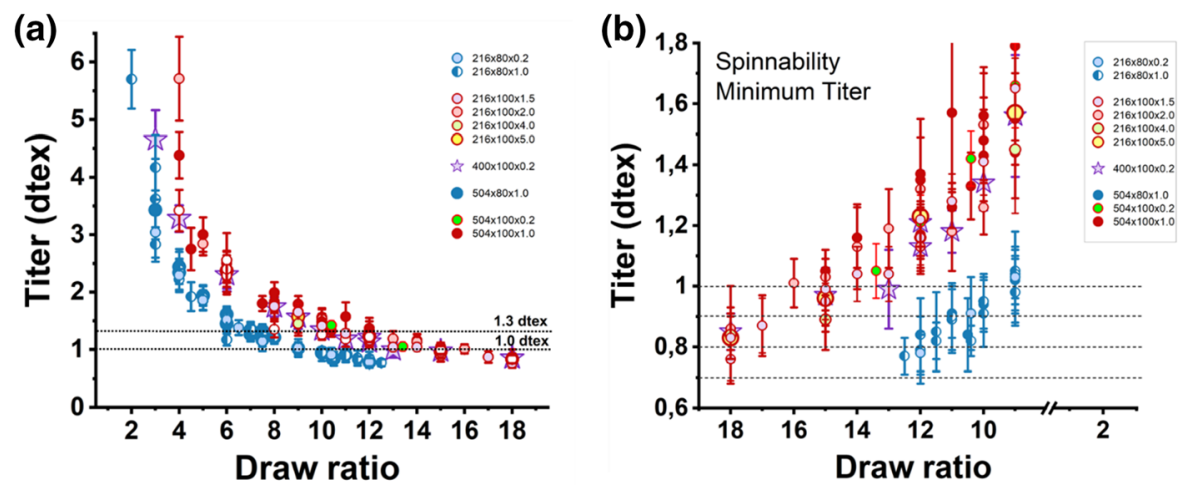

Fig.3 The titer (linear density) and draw ratio (DR) relationship of the fibers spun from different spinneret geometries a titer 0.5 - 6 dtex b titer 0.6- 1.8 vs DR 2-18. Pulp \& solvent: 13 wt\% STG cellulose concentration in [DBNH][OAc]

5 min throughout at this DR. The spinnabilities of the use of different spinnerets are listed in Table S1. In this study, all the spinnerets with hole diameter $100 \mu \mathrm{m}$ and $80 \mu \mathrm{m}$ showed good to excellent spinnabilities for both STG and HPG cellulose solutions regardless of the spinneret aspect ratio.

\section{$L / D$ ratio of the spinnerets: effect on toughness and tenacity}

According to our previous study, the longer capillary ( $\mathrm{D}=100 ; \mathrm{L}=200 ; \mathrm{L} / \mathrm{D} 2$ 2) influenced the molecular alignment of the cellulose molecule of a cellulose solution with high shear power inside the spinneret (Moriam et al. 2021b). It was reported that, the high shear flow inside the longer capillary spinneret reduced the entanglement of the polymer chains and at the same time promoted effective molecular alignment along the flow direction. As a result, fiber toughness improved considerably. Hence, the target of this study was to further study the effect of the spinneret length-to- diameter ratio (L/D) in the fiber mechanical properties, particularly in the fiber toughness when the L/D was extended up to 5 .

Interestingly, maximum tenacity and toughness were achieved at titers ranging from 1.0 to $1.2 \mathrm{dtex}$ regardless of the spinneret geometry (Fig. 4a,b). Additionally, the highest toughness and tenacities of the fibers were achieved for the spinnerets having L/D 1.0-2.0. Longer capillary of L/D 4 and 5 did not improve the fiber toughness. Due to the high shear power within the longer capillaries of L/D 4 and 5, the shear stress presumably becomes so high above a certain DR that partial cohesive fractures are likely to
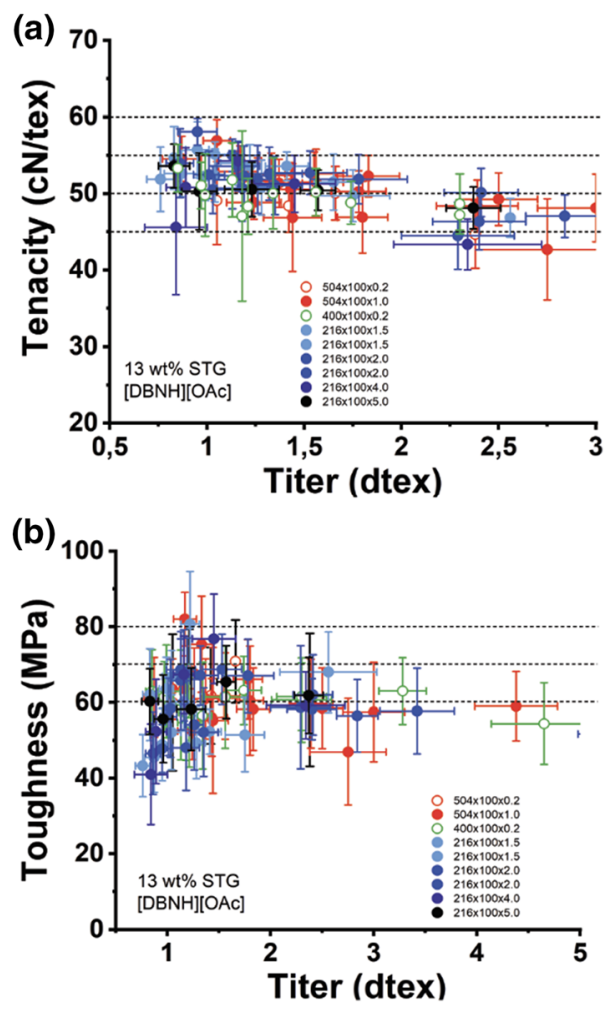

Fig. 4 The achieved a tenacities and $\mathbf{b}$ toughness of the fibers at different titers spun from D100 spinnerets with different lengthdiameter ratios (L/D 1, 1.5,2, 4, and 5). Pulp \& solvent: $13 \mathrm{wt} \%$ STG cellulose concentration in [DBNH][OAc]

occur, reflecting a stagnant or even decreasing toughness modulus with increasing DR. As a result, the fiber toughness decreased sharply at titers around $0.8 \mathrm{dtex}$ (Fig. 4a).

The contour plots further confirmed that high tenacity and toughness of the fibers were produced 
using the spinnerets with L/D ratio of 1-2 (Fig. S5a and S5b). As previously discussed, the numeric simulations showed that the shear power increased by a factor of 1.15 when L/D increased from 0.2 to 1.0-2.0. On the other hand, the shear power for L/D 4 and 5 was enhanced by a factor of 1.8 and 1.9, respectively. An optimum increase of shear power, rather than too high shear power of the solution flow inside spinneret, might be favorable for better mechanical properties of the fiber. Lundahl et al. reported in a review study a similar observation where the dry-spun CNF filaments showed maximum strength at an optimum spinning shear beyond which the mechanical properties of the CNF filament started to decrease (Lundahl et al. 2017). Another study showed that with the increased shear rate during wet spinning of polyethersulfone hollow fiber, the tensile strength and young modulus of the fiber increased but elongation at break decreased. They explained that the high shear rate promoted greater orientation and more closely packed molecular chains in the direction of shear which substantially increased the tensile strength at break but introduced higher resistance to elongation at break (Chung et al. 2000). In this study, with an increased capillary ratio of more than L/D 2 at target titer, the tensile strength did not change significantly, but the elongation at break decreased (Table S3). High shear power induced by a longer capillary (L/D > 2) might create irreversible molecular chain arrangement and restrict the elongation. Thus, the tensile strength and the young's modulus remained unchanged, but the elongation at break decreased, resulting in a slight reduction in fiber toughness. The reduction in elongation and toughness of the fiber was more prominent at the target titer ( 1.2-1.3 dtex) while using spinneret with L/D 5 (Fig. 4b, Table S3).

Furthermore, the microfibers with a titer below 1.0 dtex showed a significant reduction in toughness, especially for longer capillaries ( $/ \mathrm{D}>2$ ) (Fig. $4 \mathrm{~b}$ and Fig. S5). As the titer decreases, the elastic stress increases once all the chains reach their maximum elongated state (Bengtsson et al. 2021). At some point, the filaments get too thin that the shear stress exceeds the tensile strength of the filament leading to a gradually increasing cohesive fracture (Fisher and Denn 1976). The resulting lower lateral intercrystallite interaction causes a reduced elongation of the fibers produced (Schurz and Lenz 1994). At the same time, the modulus of elasticity increases with decreasing titer to a point where fiber breakages started during spinning (Fig. S8).

\section{Hole diameter of the spinnerets: effect on toughness and tenacity}

Since the highest toughness and tenacities of the fibers were obtained when using D100 spinnerets with L/D $1-2$, the highest aspect ratio of L/D 1 was selected for D80 spinnerets. In the case of the D80 spinneret, the effect of different spinneret capillary aspect ratios was compared between L/D 1 (longer) and L/D 0.2 (shorter). Similar to D100, the shear power of the cellulose solution inside the D80 with the spinneret of a larger L/D ratio was slightly higher than that of shorter capillary L/D 0.2 (Fig. S3). Interestingly, the tenacity and toughness of the spun fibers at target titer (1-1.3 dtex) produced using D80 was almost similar
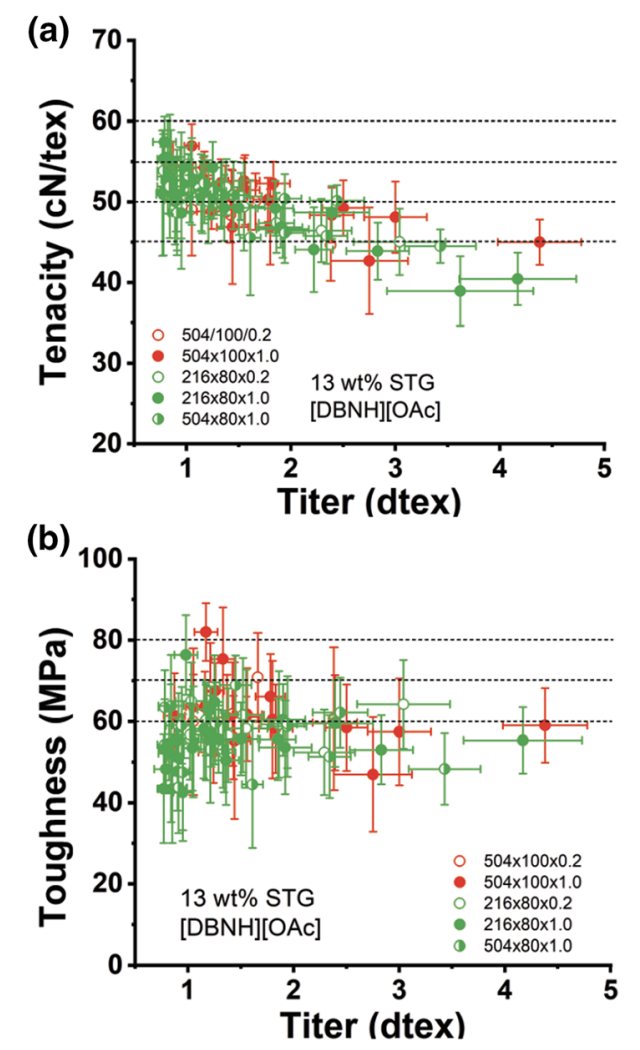

Fig. 5 The effect of different hole diameters (80 and $100 \mu \mathrm{m})$ and the capillary diameter to length ratio, L/D (short; L/D 0.2 and long capillary; L/D 1.0) on a tenacities and $\mathbf{b}$ toughness of the spun fibers at different titers. Pulp \& solvent: 13 wt\% STG cellulose concentration in [DBNH] [OAc] 
for both shorter and longer capillaries (Fig. 5a,b; Table S3). The optimum shear power might already be achieved with a reduction of the diameter from 100 to $80 \mu \mathrm{m}$, so that a further increase of the capillary aspect ratio had no influence on the mechanical properties of the fibers spun with D80. The use of D100 and D80 spinnerets showed comparable results (Fig. 5a,b; Fig. S6).

In terms of fiber toughness improvements, the 504-hole spinneret showed slight advantages over the 216-hole spinneret (Fig. 5a,b). As mentioned earlier, the required spinning temperature was lower when spinning with spinnerets with a larger number of orifices. The lower temperature of the solution means a higher solution viscosity, which is associated with a relatively higher elongational viscosity (Guizani et al. 2020b). This high elongational viscosity could contribute to the improvement of tenacity and toughness of the spun fibers.

Assessing the effect of spinneret geometries in combination with different pulp properties

\section{Effect of pulp purity: 100 and $80 \mu \mathrm{m}$ diameters}

STG fibers with highest toughness and tenacity were produced using a spinneret with L/D 1. Hence, the effect of pulp purity in the final fiber was investigated using two different spinnerets with L/D 1 (longer capillary) and L/D 0.2 (shorter capillary).

A longer capillary (L/D 1.0) was clearly advantageous compared to the shorter capillary (L/D 0.2) for achieving both high tenacity and high toughness (Fig. 6a and b). In addition, HPG with longer and more uniform molecular chains (lower polydispersity) in combination with high viscosity resulted in improved mechanical properties. A previous study indicated that a higher proportion of longer molecular chains, lower polydispersity, and fewer non-cellulosic impurities in an HPG pulp resulted in improved mechanical properties of fibers spun from it compared to fibers spun from an STG pulp (Moriam et al. 2021b). Fibers spun from HPG-IL solution with a longer capillary (L/D 1.0) further improved toughness compared to fibers spun from HPG in combination with a shorter capillary (L/D 0.2) (Fig. 6b). In combination with a longer capillary (L/D 1) and high-purity pulp, the maximum fiber toughness reached up to $93 \mathrm{MPa}$ at a titer of $\sim 1.3$ dtex (Fig. 6b,
Table S3), which can be considered the best mechanical properties achieved so far for Ioncell fibers.

In terms of both tenacity and toughness of fibers produced with D100 spinnerets, the effects caused by the combination of HPG and short capillary (L/D 0.2) and those produced by STG and longer capillary (L/D 1) were comparable (Fig. 6a,b).

In case of D80 spinnerets, fiber produced from HPG pulp also showed better mechanical strength compared to fibers spun from STG (Fig. 6c,d). However, the difference was not as prominent as it was for the fibers produced from D100 spinnerets. This might be related to the changed shear flow behavior inside the spinneret. The numerical simulation showed that when the D100 spinneret was used, the shear power increased for both longer capillaries (L/D 1) and presence of HPG dopes in the capillaries (Fig. S4). However, the two different cellulose solutions (13 wt\%) prepared from STG and HPG pulps, respectively, showed no difference in shear power when the D80 spinneret was used (Fig. S4).

\section{Pulp concentration: effect on toughness and tenacity}

In a previous publication, the cellulose concentration in a [DBNH][OAc] solution was varied from 10 to 17 $\mathrm{wt} \%$ and it was reported that the mechanical properties of the fiber were highest while using a cellulose concentration of $15 \mathrm{wt} \%$ (Sixta et al. 2015). In this study, to investigate the effect of increased cellulose concentration in the spinning solution on fiber properties, cellulose solutions containing $15 \mathrm{wt} \%$ cellulose (using both STG and HPG) were prepared and spun in comparison with solutions containing 13 wt\% cellulose.

Interestingly, the fiber properties showed no further improvement with increasing concentration, regardless of the change in the pulp (Fig. 7a-d). Rather, both fiber tenacity and toughness decreased compared to the fibers spun from $13 \mathrm{wt} \%$ cellulose concentration (Fig. 7a-d). The $15 \mathrm{wt} \%$ and $17 \mathrm{wt} \%$ cellulose solutions were previously spun (Sixta et al. 2015) with a circular spinneret in which the capillaries had a larger entrance angle $\left(60^{\circ}\right)$. However, in this study, the spinneret with rectangular hole distribution had a narrower entrance angle of only $8^{\circ}$, the latter exerting a significantly higher shear power on the cellulose solution than a spinneret with a larger entrance angle (Figure S2). Due to the high shear power, the solution 

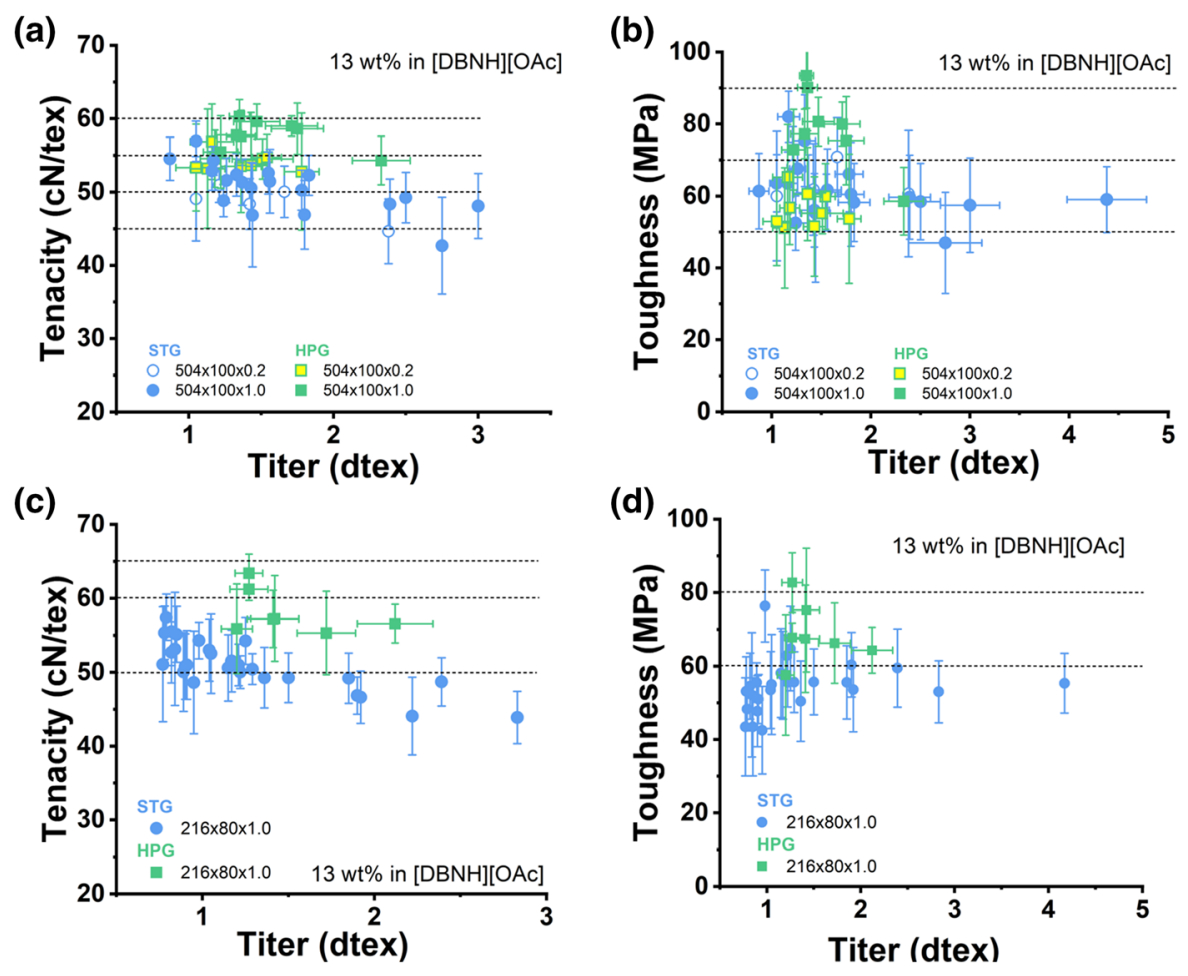

Fig. 6 Effect of STG and HPG pulps in the a tenacity and b toughness of the fibers produced using $100 \mu \mathrm{m}$ spinneret with short (L/D 0.2) and long (L/D 1.0) capillary; the effect of STG

flow might be restricted at high cellulose concentration in the dope so that the shear stress became higher with increasing zero shear viscosity (Table S4), resulting in partial cohesive fracture, which impaired the mechanical properties of the spun fibers.

Structural properties of the high toughness fibers

Both the elongation and tensile strength properties of the fiber depend on the fiber orientation (Asaadi et al. 2018). Hence, toughness, which is the integral of the tensile strength over the elongation, also depends on fiber orientation. Previous studies have shown that the degree of fiber orientation increased considerably at a lower DR and tended to level-off when greater than 5 (Michud et al. 2016). Both the total orientation and crystalline orientations of the fibers were nearly the same for the STG- and HPG-based fibers regardless of the spinneret geometries (Fig. 8). In addition, the change in crystal size and crystallinity did not correlate with the change in toughness of the fiber.

and HPG in $\mathbf{c}$ tenacity and $\mathbf{d}$ toughness of the fibers produced using $80 \mu \mathrm{m}$ spinneret having L/D 1.0. Pulp \& solvent: STG and HPG (13 wt\% cellulose concentration in [DBNH][OAc])

The average crystal size of the fibers was 34-36 A and the crystallinity was 34-36\% (Table S3).

The voids within the fiber matrix influence the mechanical properties of the fiber. In the dry-jet wet spinning process, the microvoids are elongated and formed in the spinneret (pre-orientation) and in the airgap (Schurz et al. 1995; Sharma et al. 2019). Previously, the microvoid orientation of the HPGbasedfibers were found to be lower compared to the STG fiber (Moriam et al. 2021b). It was assumed that the slightly reduced microvoid orientation of the HPGbased fiber improved the extensibility of fibers resulting in a concomitant increase in elongation properties along with the increased tensile strength. Consistent with the previous studies, HPG-based fibers produced in this study also showed reduced microvoid orientations compared to the STG-based fibers (Fig. 9). Additionally, gradual reduction in microvoid orientation was observed for the fibers with increased toughness regardless of their origins (Fig. 9).

Lyocell fibers have a skin-core structure, but with a much thinner skin (outer layer) than regular viscose 

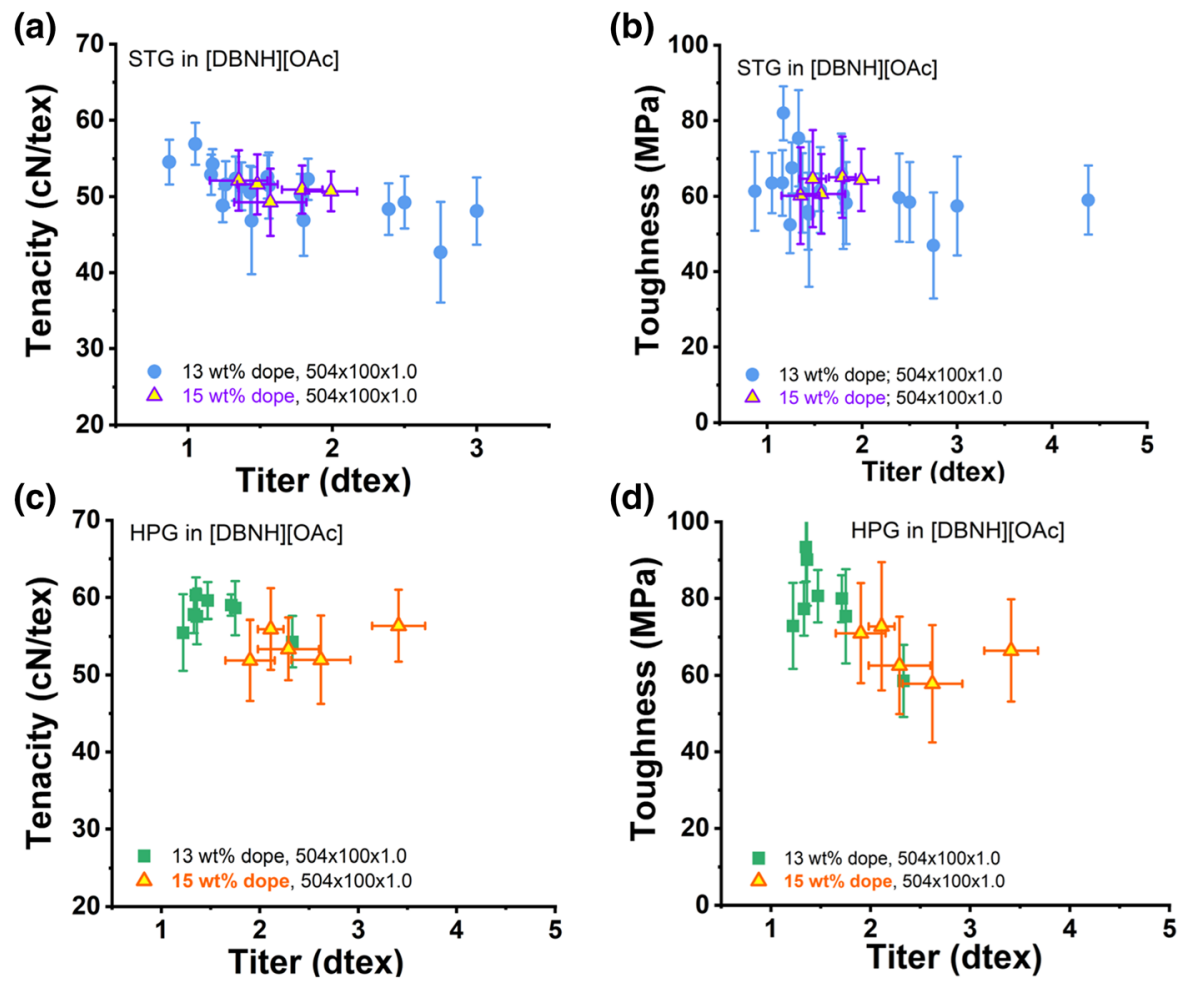

Fig. 7 The effect of increased STG and HPG cellulose concentration (13 wt $\%$ to $15 \mathrm{wt} \%$ in [DBNH][OAc]) in a tenacity and b toughness of STG-based fibers; c tenacity and $\mathbf{d}$ toughness of HPG-based fibers

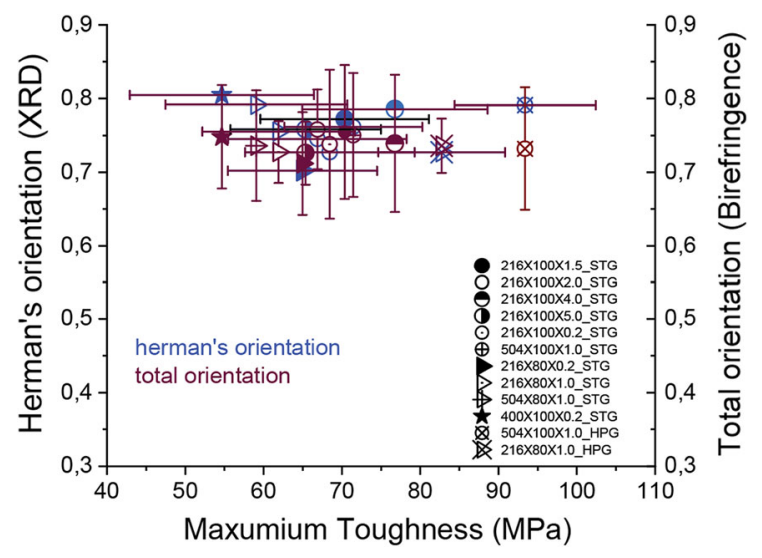

Fig. 8 The total orientation and crystalline orientation values for the high toughness STG- and HPG-based fibers spun using different geometries (in terms of diameters and capillary aspect ratio). Pulp \& solvent: STG and HPG (13 wt\% cellulose concentration in $[\mathrm{DBNH}][\mathrm{OAc}])$

(CV) fibers and an inner crystalline core consisting of nearly parallel oriented fibrils connected to amorphous domains (Biganska and Navard 2008).

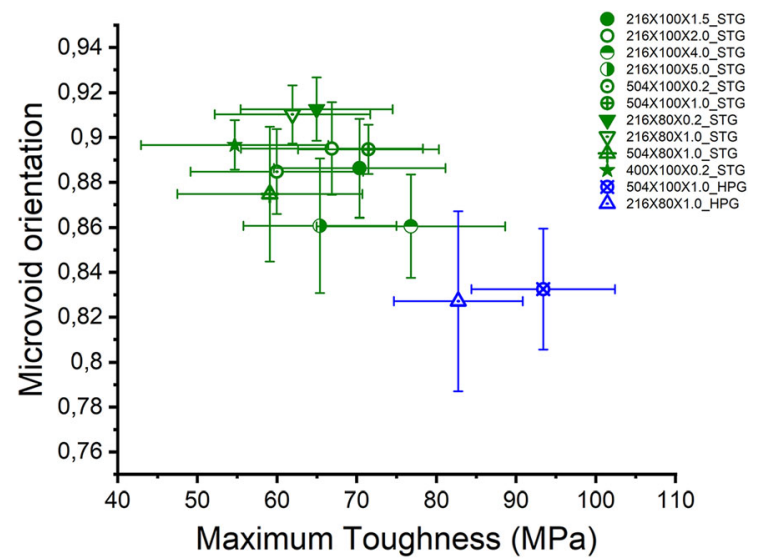

Fig. 9 The microvoid orientation of the STG- and HPG-based fibers with maximum toughness produced using different spinneret geometries. Pulp and solvent: STG and HPG (13 wt $\%$ cellulose concentration in [DBNH][OAc])

Fiber morphologies were nearly identical for all fibers prepared from HPG and STG (Fig. 10), regardless of their process parameters such as spinneret geometries and raw materials. Analogous to the lyocell fibers spun from NMMO cellulose spinning 


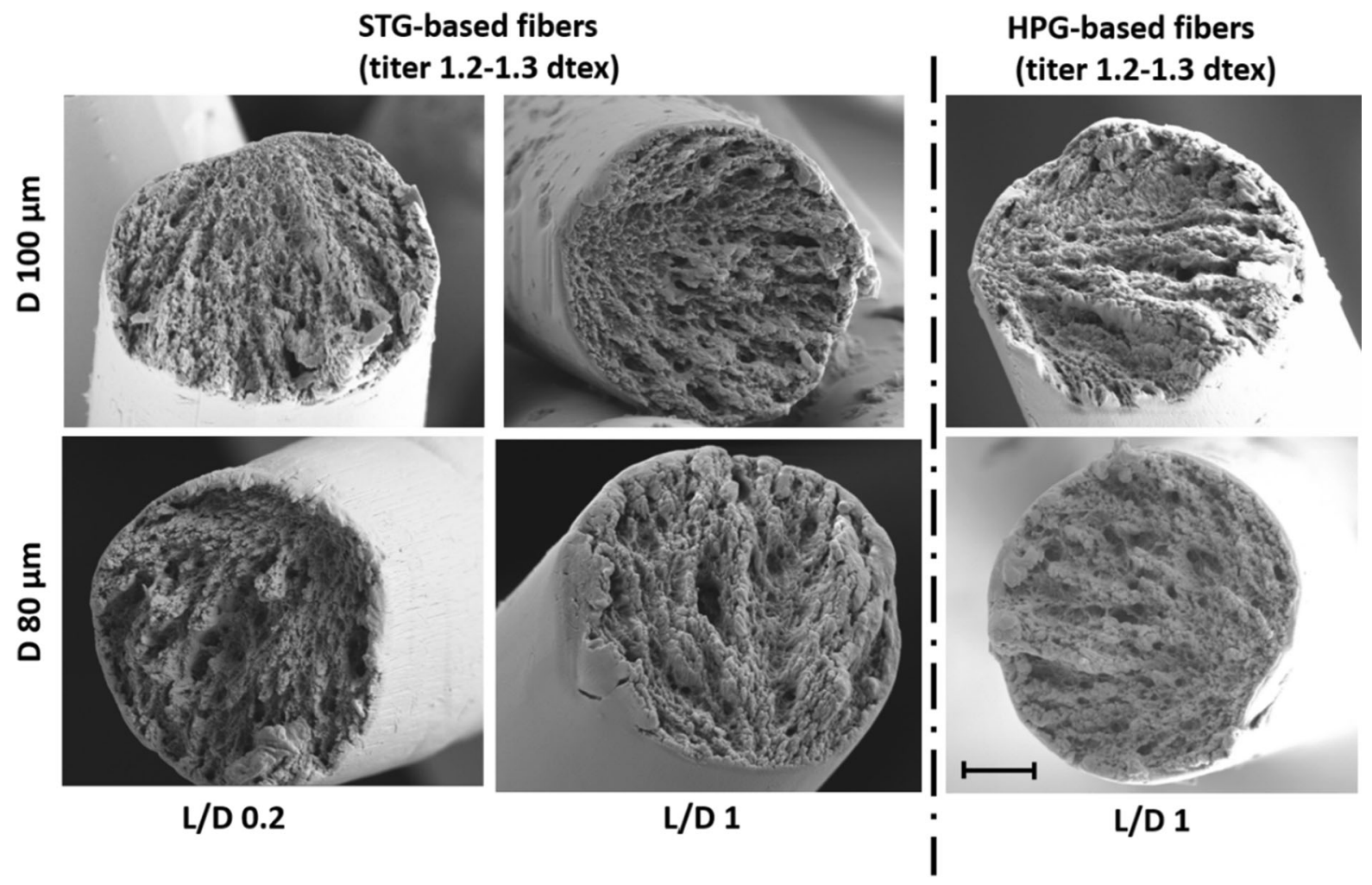

Fig. 10 The morphologies of the spun fibers of standard titer spun using $100 \mu \mathrm{m}$ and $80 \mu \mathrm{m}$ spinneret diameters (STG-based fibers: L/D 0.2 and 1.0; HPG-based fibers: L/D 1.0). Scale bar

solutions, the Ioncell fibers were exhibited a skin-core structure with a thin outer layer and an inner core from which oriented fibrils protruded surrounded by somewhat irregularly arranged voids (open pores).

Qualitatively, the diameters of the microvoids in the fibers spun with the longer capillaries, $\mathrm{L} / \mathrm{D}=1$ and a hole diameter of $100 \mu \mathrm{m}$, are larger and less oriented than those of the reference fibers spun with the shorter capillaries, $\mathrm{L} / \mathrm{D}=0.2$. These differences in the fibrillar structure of the fiber cross sections also apply to the microfibers with a titer smaller than 1.0 (Fig. S7).

\section{Conclusion}

The development of a circular economy requires strategies to produce cellulosic fibers with high toughness, as fiber toughness is the core for improving the longevity of cellulose-based textiles. Biodegradable and cellulose-based fibers from closed loop operations are the sustainable solution to meet
$2 \mu \mathrm{m}$. Pulp and solvent: STG and HPG; 13 wt $\%$ cellulose concentration in $[\mathrm{DBNH}][\mathrm{OAc}]$

challenges in the textile industry such as microplastic pollution and non-recyclable textiles. Ioncell technology has already shown tremendous potential for textile recycling and the production of cellulose-based textile fibers with superior strength properties compared to any other cellulose-based fibers on the market. In this study, certain process settings were investigated to enhance fiber toughness, giving priority to the spinneret geometry. The spinneret geometry exhibited a significant effect on the mechanical properties of the fiber spun from the ionic liquid [DBNH][OAc]. Numerical simulations showed that the flow properties of the cellulose solution changed with different spinneret geometries. The spinneret with a capillary aspect ratio L/D 1-2 provided optimized shear power of the cellulose solution, which is required for a better mechanical property of the spun fiber. Spinneret L/D 1-2 promoted the highest tenacity and toughness of the fibers. Both D100 and D80 showed comparable fiber properties. The combination of the use of highpurity pulp (13 wt\%) and the capillary aspect ratio L/D 
1 with a capillary entry cone $8^{\circ}$ of the D100 spinneret resulted in fibers with the highest toughness (93 MPa) and a tenacity of $60 \mathrm{cN} /$ tex. With the new strategies presented in this study, Ioncell fibers were able to achieve approximately $12 \%$ higher toughness as compared to the previous study (from 83.3 to $93 \mathrm{MPa}$ ) (Moriam et al. 2021b). Both total and the crystalline orientation showed no significant changes for the high-toughness fibers spun from different geometries or raw materials. The microvoid orientations were comparatively lower for the HPG-based fibers than for the STG-based fibers, while the fiber morphologies for the spun fibers were very similar at a standard titer, but still showed qualitatively larger pore structures for the HPG fibers.

Finally, this research created a new perspective for improving the toughness of cellulose-based textile fiber which will contribute to the circular economy and sustainability of textile production. Further studies will include the effect of different spinneret geometries at even larger variations on the mechanical properties of Ioncell fibers made from other ionic liquids.

Acknowledgments This project has received funding from the Academy of Finland (under the project WTF-click-nano), Jenny and Antti Wihuri foundation, Puunjalostusinsinöörit Oy and FinnCERES. The authors also gratefully acknowledge Katrina Räty for proofreading the article. Additionally, the authors acknowledge the provision of facilities and technical support by Aalto University at OtaNano -Nanomicroscopy Center (Aalto-NMC) and D22 instrument at ILL, Dr. Lionel Porcar.

Author contributions Herbert Sixta and Kaniz Moriam designed and interpreted the results of all the experiments. The manuscript was written by Kaniz Moriam as a principal author and Herbert Sixta reviewed the manuscript. All authors have given approval to the final version of the manuscript.

Funding Open access funding provided by Aalto University.

\section{Declarations}

Conflict of interest The authors declare that they have no conflict of interest.

Human and animal rights This research does not contain any experiments with human participants or animals.

Open Access This article is licensed under a Creative Commons Attribution 4.0 International License, which permits use, sharing, adaptation, distribution and reproduction in any medium or format, as long as you give appropriate credit to the original author(s) and the source, provide a link to the Creative Commons licence, and indicate if changes were made. The images or other third party material in this article are included in the article's Creative Commons licence, unless indicated otherwise in a credit line to the material. If material is not included in the article's Creative Commons licence and your intended use is not permitted by statutory regulation or exceeds the permitted use, you will need to obtain permission directly from the copyright holder. To view a copy of this licence, visit http://creativecommons.org/licenses/by/4.0/.

\section{References}

Adusumalli RB, Keckes J, Martinschitz KJ, Boesecke P, Weber H, Roeder T, Gindl W (2009) Comparison of molecular orientation and mechanical properties of lyocell fibre tow and staple fibres. Cellulose 16:765-772. https://doi.org/10. 1007/s10570-009-9292-2

Asaadi S, Hummel M, Ahvenainen P, Gubitosi M, Olsson U, Sixta H (2018) Structural analysis of Ioncell-F fibres from birch wood. Carbohyd Polym 181:893-990. https://doi. org/10.1021/acssuschemeng.8b01768

Asaadi S, Hummel M, Hellsten S, Härkäsalmi T, Ma Y, Michud A, Sixta H (2016) Renewable high performancefibers from the chemical recycling of cotton waste utilizing an ionic liquid. Chemsuschem 9:3250-3258. https://doi.org/10. 1002/cssc. 201600680

Bengtsson J, Jedvert K, Köhnke T, Theliander H (2021) The challenge of predicting spinnability: investigating benefits of adding lignin to cellulose solutions in air-gap spinning. J Appl Polym Sci 138:50629. https://doi.org/10.1002/app. 50629

Biganska O, Navard P (2008) Morphology of cellulose objects regenerated from cellulose-N-methylmorpholine $\mathrm{N}$-oxide-water solutions. Cellulose 16(2):179. https://doi.org/ 10.1007/s10570-008-9256-y

Chung TS, Qin JJ, Gu J (2000) Effect of shear rate within the spinneret on morphology, separation performance and mechanical properties of ultrafiltration polyethersulfone hollow fiber membranes. Chem Eng Sci 55(6):1077-1091. https://doi.org/10.1016/S0009-2509(99)00371-1

Fisher RJ, Denn MM (1976) A theory of isothermal melt spinning and draw resonance. AlChE J 22:236-246. https://doi. org/10.1002/aic.690220203

Elsayed S, Hellsten S, Guizani C, Witos J, Rissanen M, Rantamäki AH, Varis P, Wiedmer SK, Sixta H (2020) Recycling of superbase-based ionic liquid solvents for the production of textile-grade regenerated cellulose Fibers in the Lyocell process. ACS Sustain Chem Eng 8:14217-14227. https://doi.org/10.1021/acssuschemeng. $0 \mathrm{c} 05330$

Guizani C, Larkiala S, Moriam K, Sawada D, Elsayed S, Rantasalo S, Hummel HM (2020) Air gap spinning of a cellulose solution in [DBNH][OAc] ionic liquid with a novel vertically arranged spinning bath to simulate a closed loop operation in the Ioncell ${ }^{\circledR}$ process. J Appl Polym Sci 138(5):49787. https://doi.org/10.1002/app.49787 
Guizani C, Nieminen K, Rissanen M, Larkiala S, Hummel M, Sixta H (2020b) New insights into the air gap conditioning effects during the dry-jet wet spinning of an ionic liquidcellulose solution. Cellulose 27(9):4931-4948. https://doi. org/10.1007/s10570-020-03115-8

Haslinger S, Hummel M, Anghelescu-Hakala A, Määttänen M, Sixta H (2019a) Upcycling of cotton polyester blended textile waste to new man-made cellulose fibers. Waste Manage 97:88-96. https://doi.org/10.1016/j.wasman.2019. 07.040

Haslinger S, Wang Y, Rissanen M, Lossa MB, Tanttu M, Ilen E, Määttänen M, Harlin A, Hummel M, Sixta H (2019b) Recycling of vat and reactive dyed textile waste to new colored man-made cellulose fibers. Green Chem 21(20):5598-5610. https://doi.org/10.1039/C9GC02776A

Hauru LKJ, Hummel M, Michud A, Sixta H (2014) Dry jet-wet spinning of strong cellulose filaments from ionic liquid solution. Cellulose 21(6):4471-4481. https://doi.org/10. 1007/s10570-014-0414-0

Hummel M, Michud A, Tanttu M, Asaadi S, Ma Y, Hauru LKJ, Parviainen A, King AWT, Kilpeläinen I, Sixta H (2016) Ionic liquids for the production of man-made cellulosic fibers: opportunities and challenges. In: Rojas OJ (ed) Cellulose chemistry and properties: fibers, nanocelluloses and advanced materials. Springer International Publishing, Cham, pp 133-168

Jiang X, Bai Y, Chen X, Liu W (2020) A review on raw materials, commercial production and properties of lyocell fiber. J Bioresour Bioproducts 5:16-25. https://doi.org/10. 1016/j.jobab.2020.03.002

Kirichenko A, Kholosha V, Chernyshov YA, Il'in V, Nefedova I, Ambainis YYJFC (1977) The spinneret design as a factor in the conditions of cooling and regularity of the properties of Capron cord yarn. Fibre Chem 8(6):642-644. https://doi. org/10.1007/BF00546688

Langan P, Nishiyama Y, Chanzy H (2001) X-ray structure of mercerized cellulose II at $1 \AA$ resolution. Biomacromol 2(2):410-416. https://doi.org/10.1021/bm005612q

Lenz J, Schurz J, Wrentschur E (1994) On the elongation mechanism of regenerated cellulose fibres. Holzforschung 48(s1):72-76. https://doi.org/10.1515/hfsg.1994.48.s1.72

Lundahl MJ, Klar V, Wang L, Ago M, Rojas OJ (2017) Spinning of cellulose nanofibrils into filaments: a review. Ind Eng Chem Res 56(1):8-19. https://doi.org/10.1021/acs.iecr. 6b04010

Ma Y, Hummel M, Kontro I, Sixta H (2018a) High performance man-made cellulosic fibres from recycled newsprint. Green Chem 20(1):160-169. https://doi.org/10.1039/ C7GC02896B

Ma Y, Stubb J, Kontro I, Nieminen K, Hummel M, Sixta H (2018b) Filament spinning of unbleached birch kraft pulps: effect of pulping intensity on the processability and the fiber properties. Carbohyd Polym 179:145-151. https://doi. org/10.1016/j.carbpol.2017.09.07

Michud A, Hummel M, Sixta H (2016) Influence of process parameters on the structure formation of man-made cellulosic fibers from ionic liquid solution. J Appl Polym Sci 133(30):43718. https://doi.org/10.1002/app.43718

Michud A, Tanttu M, Asaadi S, Ma Y, Netti E, Kääriainen P, Persson A, Berntsson A, Hummel M, Sixta H (2015) Ioncell-F: ionic liquid-based cellulosic textile fibers as an alternative to viscose and Lyocell. Text Res J 86(5):543-552. https://doi.org/10.1177/ 0040517515591774

Moriam K, Rissanen M, Sawada D, Altgen M, Johansson L-S, Evtyugin DV, Guizani C, Hummel M, Sixta H (2021a) Hydrophobization of the man-made cellulosic fibers by incorporating plant-derived hydrophobic compounds. ACS Sustain Chem Eng 9:4915-4925. https://doi.org/10.1021/ acssuschemeng.1c00695

Moriam K, Sawada D, Nieminen K, Hummel M, Ma Y, Rissanen M, Sixta H (2021b) Towards regenerated cellulose fibers with high toughness. Cellulose. https://doi.org/10. 1007/s10570-021-04134-9

Mortimer SA, Péguy A (1995) 72-Spinning of fibres through the $\mathrm{N}$-methylmorpholine-N-oxide process. In: Kennedy JF, Phillips GO, Williams PA (eds) Cellulose and cellulose derivatives. Woodhead Publishing, London, pp 561-567. https://doi.org/10.1533/9781845698539.6.561

Mortimer SA, Peguy AA (1996) The influence of air-gap conditions on the structure formation of lyocell fibers. J Appl Polym Sci 60(10):1747-1756. https://doi.org/10.1002/ (SICI)1097-4628(19960606)60:10\%3c1747::AIDAPP28\%3e3.0.CO;2-\#

Männer J, Ivanoff D, Morley RJ, Lenzing SJ (2009) Tencel®New cellulose fibers for carpets. Lenzinger Berichte 2:60-71

Newville M, Stensitzki T, Allen DB, Rawlik M, Ingargiola A, Nelson AJASCL (2016) Lmfit: non-linear least-square minimization and curve-fitting for python. Science 1606:14

Royer SJ, Wiggin K, Kogler M, Deheyn DD (2021) Degradation of synthetic and wood-based cellulose fabrics in the marine environment: comparative assessment of field, aquarium, and bioreactor experiments. Sci Total Environ 791:148060. https://doi.org/10.1016/j.scitotenv.2021.148060

Salvador CF, Turra A, Baruque-Ramos J (2017) Synthetic fibers as microplastics in the marine environment: a review from textile perspective with a focus on domestic washings. Sci Total Environ 598:1116-1129. https://doi.org/10.1016/j. scitotenv.2017.04.172

Sayyed AJ, Deshmukh NA, Pinjari DV (2019a) A critical review of manufacturing processes used in regenerated cellulosic fibres: viscose, cellulose acetate, cuprammonium, $\mathrm{LiCl} /$ DMAc, ionic liquids, and NMMO based lyocell. Cellulose 26:2913-2940. https://doi.org/10.1007/s10570-01902318-y

Sayyed AJ, Mohite LV, Deshmukh NA, Pinjari DV (2019b) Structural characterization of cellulose pulp in aqueous NMMO solution under the process conditions of lyocell slurry. Carbohyd Polym 206:220-228. https://doi.org/10. 1016/j.carbpol.2018.11.004

Schurz J, Lenz J (1994) Investigations on the structure of regenerated cellulose fibers. Macromol Symp 83:273-89

Schurz J, Lenz J, Wrentschur E (1995) Inner surface and void system of regenerated cellulose fibers. Die Angewandte Makromolekulare Chemie 229(1):175-184. https://doi. org/10.1002/apmc.1995.052290112

Sharma A, Sen D, Thakre S, Kumaraswamy G (2019) Characterizing microvoids in regenerated cellulose fibers obtained from Viscose and Lyocell processes. Macromolecules 
52:3987-3994. https://doi.org/10.1021/acs.macromol. $9 \mathrm{~b} 00487$

Shen L, Worrell E, Patel MK (2010) Environmental impact assessment of man-made cellulose fibres. Resour Conserv Recycl 55(2):260-274. https://doi.org/10.1016/j. resconrec.2010.10.001

Sixta H, Michud A, Hauru L, Asaadi S, Ma Y, King AWT, Kilpelainen I, Hummel M (2015) Ioncell-F: a high-strength regenerated cellulose fiber. Nord Pulp Pap Res J 30(1):43-57. https://doi.org/10.3183/npprj-2015-30-01p043-057

Stone C, Windsor FM, Munday M, Durance I (2020) Natural or synthetic-how global trends in textile usage threaten freshwater environments. Sci Total Environ 718:134689. https://doi.org/10.1016/j.scitotenv.2019.134689

Wang J, Wang T, Xu J, Yu J, Zhang Y, Wang H (2018) Study on spinnability of polyacrylonitrile solution based on dynamics simulation of dry-jet wet spinning. J Appl Polym Sci 135:46377. https://doi.org/10.1002/app.46377

Wedin H, Lopes M, Sixta H, Hummel M (2019) Evaluation of post-consumer cellulosic textile waste for chemical recycling based on cellulose degree of polymerization and molar mass distribution. Text Res J 89(23-24):5067-5075. https://doi.org/10.1177/0040517519848159

Xia X, Gong M, Wang C, Wang B, Zhang Y, Wang H (2015) Dynamic modeling of dry-jet wet spinning of cellulose/ [BMIM]Cl solution: complete deformation in the air-gap region. Cellulose 22(3):1963-1976. https://doi.org/10. 1007/s10570-015-0613-3

Xia X, Wang J, Wang H, Zhang Y (2016) Numerical investigation of spinneret geometric effect on spinning dynamics of dry-jet wet-spinning of cellulose/[BMIM]Cl solution. J Appl Polym Sci 133(38):43962. https://doi.org/10.1002/ app.43962

Xia XL, Yao YB, Zhu XJ, Mukuze KS, Wang CS, Zhang YM, Wang HP (2014) Simulation on contraction flow of concentrated cellulose/1-butyl-3-methylimidazolium chloride solution through spinneret orifice. Mater Res Innov 18(sup2):S874-S878. https://doi.org/10.1179/1432891714Z. 000000000484

Publisher's Note Springer Nature remains neutral with regard to jurisdictional claims in published maps and institutional affiliations. 